Proc. Indian Acad. Sci. (Engg. Sci.), Vol. 6, Pt. 4, December 1983, pp. 355-371.

(C) Printed in India.

\title{
International scene in remote sensing
}

\author{
Y S RAJAN and JACOB NINAN \\ Indian Space Research Organisation (ISRO), ISRO Headquarters, Bangalore 560009
}

\begin{abstract}
A brief survey of the status of remote sensing or earth observations from space as applied to earth-bound resources management is made. Glimpses of space systems under execution and under planning are given. Utilisation of the remote sensing technology by developed and developing countries is reviewed, pointing out current problems and future potentials.
\end{abstract}

Keywords. Remote sensing; earth observations; international status; applications of satellite imagery.

\section{Introduction}

Application of space platforms for earth-bound problems was the earliest use of satellites since mankind ushered in the space era in 1957. It started with exciting pictures of earth and clouds taken by the television and infrared observations satellite (IIROs-1) in 1960. TIRos-1 was followed by a series of satellites which increased mankind's knowledge of meteorology and climatology and led to better understanding of weather. Meteorological satellite programmes are now largely accepted as being operational with many satellites of different countries and agencies operating at near earth and geosynchronous orbits. India, besides having earth stations to receive data from foreign meteorological satellites, has also a meteorological component in its Indian national satellite (INSAT) space system. A brief description of INSAT meteorological system can be found in Dhawan et al (1979). Rapid development of space technology and earth observation systems, which started with simple television cameras on tiRos, has now led to many sophisticated sensors in different parts of electromagnetic spectrum. Types of satellite remote sensing sensors developed and under planning in usA exceed 100 and a good survey of these is available in Tanner (1982). These developments in USA, USSR, Europe and other countries make it possible to study, assimilate and protect natural resources of the earth including oceans. In the mid-sixties the connection between space systems and management of earth and ocean resources would have stretched our imaginations. The remote sensing experiments on Skylab, the launch of the first LANDSAT spacecraft in 1972, the long history of meteorological satellite observations, and the use of satellite imageries and photography by many nations for various applications, not merely by those who possess the relevant space and ground systems, but also by numerous countries which do not have these-have made us all aware of the promise and potential of satellite remote sensing techniques.

This paper attempts to give a glimpse of remote sensing activities in various countries to get a general idea of the international scene. It is not exhaustive in covering all countries or any country's activity completely in detail. The reader can pursue the study 
through the references cited and numerous open literature available. For ease of coverage, the material is arranged in the form of a 'walk through' a few countries. continent-by-continent, starting from North America. Later a few examples of international cooperative experiments are given. Towards the end, the paper also addresses some issues, problems, trends and possibilities in the overall scene of remote sensing in the world.

\section{North America}

\subsection{United States of America (USA)}

USA has been a pioneer in the application of remote sensing techniques to study natural resources besides being a pioneer in meteorological applications. Through its earth resources technology satellite (ERTS) programme, presently called LANDSAT, USA not only experimented with this technique for various uses but also provided opportunity to many countries to experiment its uses in their national context. The initial list of roughly 350 experiments approved by NASA covered numerous disciplines and areas. These ranged from practical applications in crop monitoring, geological mapping and timber disease analysis, to experiments aimed at determining the best manner of presenting the information collected by the spacecraft. A good summary of LANDSAT systems is given by Sheffield (1982). The published results of use of LANDSAT data for various applications in USA and abroad are too numerous to report here, even as a summary.

USA'S NASA also pioneered the use of passive and active microwave remote sensors in the study of oceans through SEASAT satellite programme. A good description of the system is given by McCandless et al (1981). Besides the above two major programmes many remote sensors such as coastal zone colour scanner (czcs) have been experimented within the Nimbus series of satellites. Space shuttle has provided an opportunity to test a variety of sensors like shuttle imaging radar (SIR) and ocean colour experiment (OCE) instrument. Some of these are reported by Keller \& Ando (1982).

Two major agencies in USA dealing with promotion of R\&D and operations in USA are the National Oceanic and Atmospheric Administration (NOAA) and the National Aeronautics and Space Administration (NASA). NOAA's long range goal is to improve the safety and quality of life through better understanding of the earth's environment and more efficient use of its resources. NOAA manages and operates USA's civil, operational, environmental satellite systems. NOAA archives and disseminates satellite data to meet the needs of public and private users and incorporates it into research programmes. NASA plans, directs, and conducts civil research and development in space and aeronautics. Pioneering work by NASA on TIROS, Nimbus, $S k y l a b$, LANDSAT and SEASAT satellites has been a major element in the worldwide use of remote sensing.

So far USA has launched more than 50 civilian earth observation satellites since TIRos-1. While the types of sensors used and under development are about 100 , the types of satellite platforms are about 10 , with changes mainly in the sensors. One important feature in the space segment development is to experiment a few new types of sensors in aircraft platform and then in an experimental spacecraft and move them to operational use. Though LANDSAT series is called experimental, certain applications of $70 \mathrm{~m}$ resolution sensor system have nearly reached operational use within and outside 
USA. There are about 16 earth stations inside and outside USA, which receive data regularly from LANDSAT satellites and some more are being considered.

The laboratories using remote sensing data for end-use applications to agriculture, forestry, range land management, environmental monitoring etc are too numerous to be listed here. Similarly it is worth noting that many major universities have training and $R \& D$ programmes in remote sensing.

The present trend is to have interpretation systems based on mini- and microcomputers and a search is going on for universal mapping techniques to present remotely sensed data. Many industries and consultancy services are growing around this technology with business volume estimated at $\$ 10$ billion per annum.

While various applications of remote sensing in USA are reported elsewhere, the conduct of a large scale programme called LACIE (large area crop inventory experiment) is an important development worth noting. LACIE was a joint project of NASA, NOAA and us Department of Agriculture that involves testing satellite techniques for surveying and forecasting wheat production. The experiment had attempted such a prediction not only for USA but also for other countries such as USSR. The experiments used LANDSAT data together with an agro-meteorological approach to estimating yield and was capable of providing improved early-season and at harvest wheat estimates. For most of the regions studied the goal of $90 \%$ accuracy for $90 \%$ of the time was reached.

Presently in USA there is the CROPCAST system operated commercially with clients worldwide. A brief description of the system is given by Sheffield (1982).

Success in LACIE has led to another inter-agency agricultural and resources inventory survey through aerospace remote sensing - called AgRISTARS. The programme, begun in 1980, is expected to continue through 1987. Research under this programme emphasises developing information-extraction techniques for the multispectral scanner and thematic mapper flown on the LANDSAT satellites. Both accuracy and efficiency of classification techniques for small grains, corn, and soyabeans were improved in 1981. Tests in the us corn belt and in the us-Canada small grains region have verified that accurate and efficient pre-harvest crop forecasts are possible. Also remote sensing techniques have been developed to produce country-level crop statistics using an existing ground survey for ground truth.

In the area of non-renewable resources a major experiment has been the NASA-GEOSAT test case project, a joint research endeavour with private industry to evaluate remote sensing techniques for geologic mapping. The project collected and analysed remote sensing data over a series of experimental sites containing known deposits of copper, uranium, oil and gas. Results have indicated that analysis of remote sensing measurements can yield geological information not commonly obtained by conventional field mapping.

Thus a notable feature in the applications projects is to move towards large scale operational systems and deeper involvement of end users and industry.

As regards remote sensors and space segment, the space shuttle provides a unique opportunity to test variety of sensors-shuttle imaging radar (SIR), multispectral optoelectronic modular scanner (MOMS), metric camera, microwave remote sensing experiment (MRSE) etc. Perhaps in view of increased costs in developing variety of sensors many of these sensor systems have an element of international cooperation mainly from Europe.

Since reduction of turn around time in data dissemination is also an important element in the use of remote sensing, systems to transmit received remotely sensed data 
to distant places through use of geostationary communication satellites are being thought of and experimented with.

The use of tracking and data relay satellite system will further reduce the number of earth stations required for complete global coverage of remote sensing from 16 to about 6.

After such major pioneering, well rounded, research and development efforts in the applications of remote sensing, USA is presently in the process of reorienting its entire activity towards operationalisation and commercialisation. Many of the major future programmes of R\&D nature like SEASAT follow on satellites, STERFOSAT etc, are yet to be approved.

\subsection{Canada}

Remote sensing in Canada has primarily concentrated on the reception, processing and use of signals received from aircraft platforms or foreign satellites. Reception of data from USA meteorological satellites began in 1963. The resource-management applications of remote sensing began with the reception of imagery from LANDSAT. Reception stations of the Canadian Centre for Remote Sensing (CCRs) at Prince Albert, Saskatchawan and Shoe Cove, Newfoundland provide data to Canadian users. Economic applications used successfully in Canada include crop inventory, forest and wildlife management, ice reconnaissance, and mineral and petroleum exploration. A programme RADARSAT, is now underway to define mission requirements, to conduct R\&D programme and conceptual design for a Canadian radar satellite primarily to provide Arctic operators with all weather ice movement information required for safe and efficient exploitation of energy resources. Participation in cooperative satellite programmes with other nations is also being pursued particularly with European Space Agency (ESA) in the development of the ERS-1. More details are available in a document by Anon (1982a).

\section{Latin America}

\subsection{Argentina}

Argentina's National Commission for Space Research (CNIE) has a remote sensing centre. This centre manages two important technical areas: the research and applications area, and the LANDSAT data acquisition, processing and distribution area. Laboratories relating to research and application area are equipped with interactive Bendix system, Optronics high resolution colour film recording system, airborne Bendix multispectral scanner, interactive Ramtek terminal with IBM/370 computer and an airborne multicamera photographic system. Research and applications programmes include crop evaluation, geological and mining surveys with purchased software package, flood study in the province of Buenos Aires, water and ground study at Mesopotomy by automatic and visual analysis, pollution studies jointly with German Space Agency, DFvLR, forestry evaluation and analysis of Chubut river lower valley.

LANDSAT data receiving facility is situated at Mar Chiquita and data processing and distribution Centre at Buenos Aires.

Additional information is available in Anon (1982b). 


\subsection{Brazil}

Brazil entered the field of remote sensing very early, being one of the first countries in the world to instal a ground station to receive data from LANDSAT. The Institute of Space Research, INPE, is responsible for this activity. The LANDSAT station at Cuiaba-MT allows a coverage of the greater part of South America. The processing and dissemination centre is located at Cachoeira Paulista, SP. The INPE supplies users with black and white and colour mss imageries as well as computer compatible tapes (CCT). This station is being upgraded for reception of data from LANDSAT -4 and SPOT. There is also an aircraft with several sensors (RC-10, $\mathbf{I}^{2} \mathrm{~S}$, PRT-r, Hasselblad). There are two automatic image analysis systems tiz, GE-Image-100 and Bendix MDAS for multispectral image analysis.

The application of remote sensing techniques is being studied in several areas like survey and control of potential mineral deposits, crop identification and area estimation, monitoring and management of natural and artificial forest lands etc. The use of data from meteorological satellites and LANDSAT is being explored in the areas of ocean resources and environmental analysis. Crop forecasting is being attempted using similar data. Cartographic mapping using LANDSAT data to an accuracy of 100 to $150 \mathrm{~m}$ is being carried out.

INPE, with the participation of Brazilian industries, is planning the development of two small scale remote sensing satellites, one for the relay of data collection platforms (DCP) and the other for remote sensing at optical frequencies, to be launched by a Brazilian launcher in the 1987-1990 period.

Further details are given in the national paper from Brazil at the UNISPACE-82 Conference at Vienna (Anon 1982c).

\section{Western Europe}

Western Europe has been active in application of earth observation techniques from the beginning. Initially many countries in Europe participated in multispectral aerial surveys and reception of data from USA's satellites. Later, European countries started having, in addition to receiving data from USA's satellites, space segment of their own through ESA and also in some cases through national space segment. Recently through some of the national programmes like French SPOT (systeme probatoire d'observation de la terra), some of the contributions to space shuttle based sensors like MRSE, SIR, MOMS etc and also ESA's major European remote sensing satellite ERS-1, Europe has not only reached a high level of technology in remote sensing but also is pushing forward the frontiers set up by usa earlier.

In addition, to advance the application of remote sensing to end uses many European laboratories/institutions have jointly formed a European Association of Remote Sensing Laboratories (EARsel.) to encourage European research and to promote concerted efforts therein, in all the disciplines of remote sensing, to facilitate scientific exchange between participating laboratories, to identify priority areas for research and to foster cooperation. EARSel brings out periodic newsletters and have established many working groups to study various disciplines. A brief description of this role of EARSeL and member laboratories is given by Barret (1982). 


\subsection{European Space Agency}

ESA has been involved in various aspects of remote sensing from the early-seventies. A number of studies have been undertaken relating both to the physics and technology of various remote sensing techniques, and to a number of specific satellite concepts.

EARTHNET, a European network to receive, reprocess and distribute earth resources satellite data, became operational in 1978. This includes four receiving stations at Fucino (Italy), Kiruna (Sweden), Lannion (France), Maspalomas (Canary Islands) and two synthetic aperture radar (SAR) processing centres at Farnborough (UK) and Oberpfaffenhofen (FRG). EARTHNET has received data from LANDSAT-1, 2, 3, HCMM, $N i m b u s-7$ and SEASAT and is being upgraded to receive data from LANDSAT-4. It will also form the ground network for the ESA remote sensing satellites.

Two European experiments in remote sensing are being planned for the Spacelab missions. The first one is for assessment of the possibilities of using very high resolution $(10-20 \mathrm{~m})$ photographs using a metric camera. The other one is to operate a microwave experiment as a two-frequency scatterometer, synthetic aperture radar and a radiometer.

ESA is planning to launch ERS-1 satellite in 1987 which will have three remote sensing payloads. The active microwave instrumentation (AMI) operates in the C-band as a synthetic aperture radar, a wave scatterometer and a wind scatterometer. A radar altimeter operates in the $\mathrm{K}$-band to determine wave height. An along track scanning radiometer (ATSR) will carry out infrared radiometric determination of sea surface temperatures.

The METEOSAT programme is ESA's first meteorological satellite programme, METEOSAT-1 was launched in November 1977 and METEOSAT-2 in June 1978. The European meteorological offices are at present preparing with the help of ESA the operational METEOSAT programme which foresees the launch of three to four METEOSATS during the period 1986-1994. More details of ESA programmes are given in Lennertz (1982).

\subsection{Federal Republic of Germany (FRG)}

FRG has been very active in the field of remote sensing, both in the application studies as well as the development of hardware. As a member of ESA, FRG has been receiving LANDSAT data from EARTHNET and extensive studies have been carried out in the development of interpretation techniques. The DFVLR is the main agency in the country for undertaking such work, although many universities and commercial organisations also play a great part. DIBIAS is a digital interactive image processing system developed for remote sensing applications. A high resolution metric camera is being developed for use on Spacelab for cartographic applications.

DFVLR is also engaged in different aspects of microwave remote sensing. Much work is being done on the use of SEASAT SAR data using a software package imported from Canada. DFVLR has tested its side-looking airborne radar (SLAR) in joint campaigns with ISRO, and an airborne SAR is also under development. A SAR 580 campaign was conducted using a Canadian SAR over Germany, FRG is developing a microwave remote sensing experiment (MRSE) for Spacelab which will work as scatterometer, radiometer and SAR and also there are plans to develop a SAR facility for Spacelab. This country also will take a leading role in the development of ERS-1 of ESA. 


\subsection{France}

CNES, the French Space Agency is actively involved in the field of remote sensing, supported by several universities and commercial organisations. LANDSAT data processing, analysis and interpretation has been going on for several years. Several instruments including radiometers, scanners, interactive image processing systems, and various equipment for photographic usage of satellite data have been developed in the country.

The major programme in remote sensing is the French national programme on the SPOT satellite. SPOT marks a major milestone in remote sensing satellites with high resolutions $(10 \mathrm{~m})$, stereoscopic observations and commercial utilisation. A company called SPOT IMAGE has been organised to sell the imagery. SPOT data has been simulated using aircraft flights. More data on SPOT is available from Cazenave (1978).

CNES has also collaborated with NASA in the use of a SEASAT prototype SAR on an aircraft, over France and also over Africa to coincide with the flight of SIR-A on the US space shuttle. Studies are still being carried out on the use of SEASAT SAR data.

France has several commercial firms with advanced technological capabilities, specialised in several aspects of remote sensing, as well as other areas. These contribute to the development of hardware for sensors as well as for applications oriented work.

\subsection{Sweden}

The Swedish Space Corporation (ssc) was established in 1972 and it is responsible for the management of the remote sensing satellite data acquisition station at Kiruna and also for the technical execution of national remote sensing programmes. The major activities undertaken by the universities are microwave radiometry, spectral signatures and image analysis using satellite images and registrations from airborne or land-based sensors. An operational/pre-operational mobile lidar system has been developed for remote sensing of air and water pollution. Three operational systems using SLAR and IR/UV scanner are being used for airborne surveillance of oil spill in the Baltic Sea. The use of LANDSAT data for mapping of clear cuts and surveillance of lake water quality has been established in Sweden. The Laboratory of Remote Sensing, University of Lund is concentrating on studies on monitoring methods for desert lands in Sudan, Tunisia and Kenya. Sweden is cooperating with France in the sPor satellite project (Anon 1982f).

\subsection{United Kingdom}

The Remote Sensing Unit of the Royal Aircraft Establishment (RAE), Farnborough is the national agency for all the remote sensing activities in the country. The National Remote Sensing Centre was established as a part of this in 1980 , to supply remote sensing data, to provide facilities for research and development of image processing and interpretation, to provide training in remote sensing etc. RAE has a ground station at Lasham to receive meteorological data from NOAA, METEOSAT and GOES satellites and another at Oakhanger which was used to receive data from SEASAT. UK obtains LANDSAT imagery through the EARTHNET stations at Kiruna (Sweden) and Fucino (Italy).

One of the main facilities at NRSC is the IDP 3000 interactive image display system operating with a Prime 300 computer. The Space Department has two Prime 750 
computers, one used for general purpose image processing and the other, along with an array processor is used for SAR processing. There are several GEMS image display systems in use.

The Department of Industry sponsors many activities in remote sensing in the country. In addition there are many institutions and firms operating airborne remote sensing services and development programmes. Multispectral cameras, microwave radiometers, SLARS, SARS and other instruments are being developed by various industries. Also, many studies have been undertaken for ERS-1 payloads. UK payloads have been flown in Nimbus satellites.

One of the most beneficial applications of remote sensing has been in the analysis of geological structure for detecting mineral deposits. In the field of agriculture and forestry, crop classification, yield forecasting monitoring diseases etc have been pursued. It has been possible to map the peat resources and bracken in the Scottish islands. LANDSAT imagery has been used in the monitoring of organic pollution in water and coastal erosion, land use planning and cartography etc. RAE was one of the major centres for SEASAT data processing, especially for SAR, and data processing and interpretation are still going on. In 1981, RAE was also involved in the flight of a Canadian Convair 580 aircraft carrying SAR in X, C and L-Bands over many places in Western Europe.

More details are given in Lindsay (1981) and Anon (1982g).

\section{Eastern Europe}

\subsection{Poland}

The Remote Sensing Centre opolis was created in 1976. Many specialists in this centre have been trained in USA, Canada, Netherlands, UK, USSR and France. OPOLIs is equipped with devices for remote sensing data acquisition and processing. These include the Japanese NAC MB 490 and AC 470 multispectral cameras, the Hasselblad 500 EL and MK70 cameras, the NAC AC-90B and AC-70 additive viewers, the electronic and analogue converter MCDS $420 \mathrm{EP}$, the Joyce-Loebel $3 \mathrm{cs}$ microdensitometer, the interpretoscope made by Zeiss-Jena, the Optronics Photomation P1700 electronic and analogue converter, and the 2PAAC system made by OVAAC8, Canada.

Poland obtains LANDSAT imagery from the Italian station at Fucino and Soviet photographs from Salyut stations and unmanned spacecraft. LANDSAT data and radar (SLAR) imagery have been used in the study of tectonic structures and other geological features. Satellite imagery have also helped in the study of hydrology and groundwater exploration, location of faults in the proposed locations of power stations, discovery of a large brown coal deposit etc. Combined use is made of aerial photography, imagery in thermal infrared and radar bands and satellite imagery for the interpretation of data (Anon 1982c).

\subsection{USSR}

Remote sensing of the earth's resources began early in the USSR due to the vastness of the territory and the recognition of its need for short and long range economic 
planning. Surveys are made with the Antonov AN-30 aircraft equipped with cameras for oblique and vertical filming, radar, microwave radiometers and radio altimeters. The Cosmos series of satellites which began in 1962 have carried many equipment like vidicon cameras and microwave sensors used for earth remote sensing. The Soyuz manned spacecraft and the Salyut manned space stations have been used extensively for photography from space using the MKF-6M multispectral camera developed jointly with the German Democratic Republic. These photographs have been used in the study and solution of various problems on the earth's surface (Popescu 1982).

The Meteor Priroda programme, using the Meteor series of weather satellites, began in 1974, and was designated for earth resources sensing. Several satellites have been launched in this series. The mainframe of these satellites is the radio TV Complex (RTVC) consisting of two opto-mechanical multispectral scanners of low (MSS-M, $1.7 \mathrm{~km}$ resolution) and medium (MSs-s, $240 \mathrm{~m}$ resolution). A later satellite carried three other scanners, one using conical scanning, one using $C C D$ array linear scanning and the third one called 'Fragment' which had 8 spectral channels. More details of these systems are given in Sidorenko (1982).

More than 30 institutions of the Academy of Sciences, USSR, are working in the area of remote sensing. The multispectral data are received at the main stations of the State Hydromet Committee in Moscow, Novosibirsk and Khabarovsk. Low resolution data are received in the automatic picture transmission (APT) at various places. At the receiving stations the information is recorded on magnetic tape and film. The data products are mainly on film and the system is oriented mainly for visual or visual instrumental interpretation of photographs. Digital information from 'Fragment' is processed in the interactive computer mode at the Institute of Space Research and the State Hydromet Committee.

The Soviet analysis of experience shows that remote sensed data is valuable for the study of the earth's natural resources, facilitating the solutions of problems like monitoring the status of agricultural lands, search for areas of increased bioproductivity in the seas, etc. The ussR Ministry of Geology is one of the main users of satellite data. Satellite imagery has been used for exposing and determining the tectonic structures and features of the earth's crust, for locating possible oil and gas bearing structures in a few places and coordinating of gold ore manifestation in one place. Other uses have been for the detection and arrest of spread of forest fires and forest outline mapping, study of the dynamics of the Danube delta, study of coastal relief etc. Remote-sensed data have also been used to study soil cover and salination, vegetation types, snow cover, crop forecasting etc. Many details are available from Sidorenko (1982), Sagdeev et al (1978) and the USSR paper at UNISPACE-82 (Anon 1982c).

\section{Africa}

\subsection{African Remote Sensing Council (ARSC)}

Realising the potential applications of remote sensing to the continent of Africa, the ARSC was formed a few years ago, with several African countries as members and with the support of the UN Economic Commission for Africa. The ARSC aims at coordinating the activities of the various member countries in this field. This includes 
the establishment of regional remote sensing centres, training programmes, operation of data reception centres, sensitization of user agencies to potential applications etc. The ARSC seeks to make good use of expertise from abroad to set up facilities, train personnel and also to cultivate international cooperation. The three regional centres are in Kinshasa (Zaire), Nairobi (Kenya) and Ouagadougou (Upper Volta) (Anon 1982h).

\subsection{Egypt}

The Remote Sensing Centre (RSC) in Egypt was established in 1971 with the cooperation of the us Government. This Centre is responsible for large scale application of LANDSAT imagery and carries out various projects along with universities and Government departments in the USA, European and French space agencies, and several agencies of the UN.

RSC has accumulated a large inventory of sophisticated instruments and processing equipment for remote sensing applications. These include a twin engine aircraft, Bendix $\mathbf{M}^{2} \mathrm{~S}$ multispectral scanner, infrared thermal mapper $\mathrm{LN}-3, \mathrm{I}^{2} \mathrm{~S}$ multispectral camera, RC-8 aerial cameras, airborne aeromagnetic system, airborne gamma-ray spectrometer, Barnes precision radiation thermometer, infrared thermal scanning systems, multispectral data analysis system M-DAS and various others.

The entire area of Egypt and Sudan has been covered by accurate and standardised geological, structural lineation and drainage maps and in parts by soil, vegetation, landuse, groundwater potential and petroleum, mineral and construction materials maps. The Centre is expanding its activities in the fields of remote sensing and photointerpretation for integrated surveys, geography, town planning, archaeology, coastal engineering, urban development, soil conservation, river basin studies etc. The Centre also conducts training programmes in various aspects of remote sensing. More details can be obtained from the UNISPACE-82 report (Anon 1982c).

\subsection{Kenya}

Kenya has recognised the importance of remote sensing as applied to resources inventory and management. One of the regional centres of ARSC is in Nairobi, Kenya. An earth station is planned to be set up at Nairobi for the reception of satellite data. At present, LANDSAT imagery is being obtained from the USA. The data are analysed and interpreted mainly using visual techniques and some studies using digital techniques have been conducted using foreign collaboration.

The areas of current interest are crop detection and monitoring, soil survey, habitat mapping, forest mapping, geological mapping, disease and pest detection, coastal environment and oceanography, cartography and demography. (Anon 1982c).

\subsection{Nigeria}

The Department of Forestry in Nigeria has a cartographic/printing/remote sensing unit. This unit is equipped with facilities for aerial photography processing and LANDSAT and SLAR imagery processing and interpretation. Remote sensing imagery processing is carried out using EARTHVIEW System-II, high resolution multiband image 
processor. Along with UNDP/FAO experts, Nigeria is working on various areas like arid zone afforestation, erosion control, fire protection and forestry wild life. Some of the major projects which have been conducted are survey and assessment of forest products, periodic cartometric estimation of different vegetation and land use types, compilation of geomorphology and administrative maps to aid interpretation of remote sensing data and high forest inventory mensuration production of land use and vegetation maps of the whole of Nigeria using SLAR (Anon 1982c).

\section{Asia}

\subsection{Bangladesh}

The Bangladesh Space Research and Remote Sensing Organisation (sParrso) carries out various activities connected with data reception, processing and applications. Presently, it has a facility for data reception from TIROS/NOAA, Meteor and GMS satellites. LANDSAT data are being obtained from abroad and a ground station for the reception of data from LANDSAT-4 and SPOT is being installed. The main mode of data analysis is visual interpretation. A Vizir image processing system (vIPS-16/55) is available for digital processing of data to obtain imagery on film.

A number of studies like crop pattern determination, crop estimation, land use, surface water distribution, river course monitoring, forestry planning, geological mapping, fishing habitat characteristics etc are being taken up. It is being planned to conduct an infrared survey using aircraft from foreign firms. SPARRSo also plans to establish a national capability for aerial photography (Anon 1982c).

\subsection{China}

Remote sensing activities in China are carried out under the direction of the National Remote Sensing Centre. The activities involve development of remote sensing instruments and digital image processing systems, research on spectral signatures and its application and the application of remotely-sensed data to different fields of national economy. The various sensors like airborne multispectral cameras, multiband scanners, microwave radiometers etc have been developed. An 11-band multispectral scanner is being developed along with airborne CCD cameras also. An X-band SAR has been developed and successfully flown yielding a $15 \times 15 \mathrm{~m}$ resolution. A LANDSAT receiving station is operating at Beijing.

Much of the interpretation work has been through visual techniques, though some digital systems have developed which use general purpose computers. Efforts are under way to produce indigenous digital image processing systems and computers. LANDSAT and aerial imagery have been used for studying possible applications, such as compiling a geological structure map of China, hydrogeological survey of arid and semi-arid areas, selection of railway paths and major construction sites, land resources mapping, water conservation with regard to distribution and pollution, oil spill monitoring etc. China plans to use remote sensing techniques more extensively in future using more digital processing methods. More details are given in Chen (1981) and Chen et al (1981). 


\subsection{India}

The Department of Space, through the Indian Space Research Organisation (ISRO) and the National Remote Sensing Agency (NRSA) has established various facilities for the acquisition, processing and interpretation of remote-sensed data and also interacts with the many user agencies. ISRO develops hardware and software for aircraft and spacecraft-based remote sensing. NRSA operates the data receiving and processing station for LANDSAT at Hyderabad in addition to the operation of remote sensing aircraft flights.

Among the sensors developed at ISRO are thermal scanner and multispectral scanners for aircraft, super vidicon cameras for spacecraft (Bhaskara), CCD-based cameras for aircraft, ground truth radiometers, microwave radiometers for spacecraft (Bhaskara), SLAR and ground-based microwave radiometers and scatterometers. NRSA has acquired a Bendix $M^{2} S, I^{2} S, P R T-5$ radiometer, geophysical equipment, RMK-15/23 cameras etc. NRSA has also developed a 6-channel chlorophyll scanner with assistance from FRG and also an X-band SLAR. There are 4 aircraft used for remote sensing surveys.

Two experimental remote sensing satellites (Bhaskara) have been developed by ISRO, which carried two-band TV cameras and microwave radiometers. The RS-D1 and RSD2 satellites carried solid-state imaging systems for landmarks sensing and classification. The IRS satellite is being planned for launch in 1985, which would carry solidstate cameras in 4 spectral bands with 37 and $73 \mathrm{~m}$ resolutions.

ISRO, at its Space Applications Centre, has established a data products laboratory for bulk processing and precision processing remote sensed data from aircraft and spacecraft. An interactive digital image handling and display system has been developed for various processing functions. A vax-11 computer system has been installed for image processing. At NRSA, the data from the LANDSAT ground station are processed in a Bendix M-DAS system. For processing of LANDSAT-4 TM data, a VAX-11 based system has been installed.

India plans to implement a National Natural Resources Management System (NNRMS) after various experiments have been conducted in order to promote and sustain the utilisation of remote sensed data for national development. It is also planned to establish 5 interactive image processing systems in different locations mainly for training in machine processing of data.

Various areas of study include groundwater exploration, agricultural and forest mapping, hydrology studies of river basins, crop monitoring, water pollution monitoring, geological mapping for tectonic features, faults, lineaments etc, soil mapping, soil salination, water run-off, land use etc (Bhavsar et al 1981, Rajan \& Rao 1982)

\subsection{Indonesia}

Starting with the use of LANDSAT data from 1972, remote sensing activities have been undertaken in Indonesia for various applications like transmigration sites planning, geological mapping, mineral exploration, soil survey and updating of base maps and thematic maps. In addition, airborne remote sensing surveys have been conducted in certain areas in the visible, near-infrared and thermal infrared bands. Among the experiments using aircraft are surveys for land use planning, assessment of hot water 
pollution, underground freshwater location, evaluation of river bases, rice cultivation areas, archaeological sites and plankton concentrations in coastal areas.

The various agencies involved in remote sensing have facilities for photoprocessing and visual interpretation. Equipment for digital image processing are being installed. Indonesia has a LANDSAT data receiving station near Jakarta (Anon 1982c).

\subsection{Japan}

The National Space Development Agency of Japan (NASDA) is responsible for the research and development of satellite remote sensing technologies. NASDA is assisted by universities and industries too.

The Earth Observation Centre at Hatoyama was placed in operation in 1979 for data reception from LANDSAT -2 and 3 . This ground station has been upgraded to receive and process data from LANDSAT-4. The data processing system makes corrections for radiometric and geometric errors and produces imagery on CCT and film.

From 1979, investigations have been going on in the areas of land use mapping, detection of suitable land for agriculture crop inventory, soil productivity, detection of forest damage, geological structure, volcano tectonics, mineral resources, snow cover, detection of fishing ground, marine pollution, disaster monitoring and prevention etc using LANDSAT imagery, aircraft, SAR etc.

Japan is also planning to launch a marine observation satellite, mos-1 by 1986 , which will contain a multispectral electronic self-scanning radiometer (MESSR) with 4 channels in the visible and near-infrared region with a resolution of $50 \mathrm{~m}$, a visible and thermal infrared radiometer (VTIR) in 4 bands with $900 \mathrm{~m}$ and $2.7 \mathrm{~km}$ resolution and a twofrequency microwave scanning radiometer (MSR) with 23 and $32 \mathrm{~km}$ resolutions. Also under plan is an earth resources satellite, ERS-1, which is to carry an L-band SAR with $25 \mathrm{~m}$ resolution and a 4-band visible infrared radiometer (VIR) with $25 \mathrm{~m}$ resolution. Details are given in Anon (1982e).

\subsection{Pakistan}

The Pakistan Space and Upper Atmosphere Research Commission (suparco) is responsible for the remote sensing activities in the country. In 1976, SUPARCO and NASA jointly set up a portable LANDSAT ground receiving station for about 12 months. A Remote Sensing Applications Centre (RESACENT) has been established at Karachi to carry out investigations based on satellite remote sensing data for natural resources survey. This Centre is equipped with density slicer, colour additive viewer, stereoscopes etc for visual interpretation of photographic data. Computer-aided data analyser is being added.

Apart from conducting research, RESACENT provides a link between the space science and technology and various agencies and Government departments engaged in water management, agricultural studies, forest surveys, flood mapping etc. On-going activities are in geological and mineral surveys, cotton crop pest infestation studies, snow melt and water run-off, afforestation studies, preparation of land use maps etc. The long term plans of sUPARCo includes developing and launching small-sized remote sensing satellites (Anon 1982d). 


\subsection{Sri Lanka}

In $1972 / 73$, a proposal was submitted to NASA for the utilisation of LANDSAT imagery to survey and monitor agricultural resources. As a result, an understanding was gained about the usefulness and the limitations of the use of satellite imagery. The second project, under USAID funding, developed an in-house capability for the processing of LANDSAT data in both photographic and digital modes, including the processing of CCTs using a small general purpose computer. Because of the small size of the country, more emphasis was given to simpler types of visual interpretation techniques and the use of general purpose computers and microprocessors rather than to highly sophisticated and specialised equipment. A Swiss/Sri Lanka Satellite Imagery Interpretation Project is going on for the monitoring and assessment of rice growing areas using LANDSAT imagery. LANDSAT data is being obtained from the Indian receiving station (Anon 1982c).

\subsection{Thailand}

Activities in remote sensing began in 1971 with the appointment of the National Remote Sensing Coordinating Committee. Many training Workshops and seminars were conducted with the help of us experts. Many Thai scientists were trained in the us, Canada, Japan, France and other places. The greatest contribution of LANDSAT imagery in Thailand has been in agriculture, in the differentiation of major crops, estimation of crop acreage and yield forecasting. Satellite data have also been used to assess damages from floods, storms etc. Other applications have been in forest mapping, identification of watershed areas, land use mapping, preparation of tectonic maps, location of fishing areas, water resources management, flood monitoring etc. The plan is to implement more machine processing of remote sensed data and various algorithms are being tried out. A landsat ground station, outside Bangkok supplies data regularly (Anon 1982c).

\section{Australia}

Research in various aspects of space science is carried out in Australia by the Commonwealth Scientific and Industrial Research Organisation (CSIRO) and various universities. Because of its large area and a small population concentrated in a few urban centres, Australia can make effective use of remote sensing techniques.

The LANDSAT receiving station at Alice Springs covers Australia and the surrounding areas. The station is equipped for the reception and the processing of MSs data is done at Canberra. There is not much facility for interactive data analysis. There are 'browse centres' in the State capitals where users can examine the 'quicklook' data before ordering for data products.

About half of the data products are bought by the mineral exploration industry, especially the large mining companies, with large investments in interactive data analysis equipment. The other major effort in the wide-scale wheat production monitoring pilot project for developing digital methods for LANDSAT data analysis. Attempts are also being made in the areas of crop inventory, pasture condition 
assessment, vegetation classification, forestry and rangeland monitoring etc. More details are given in the Australian paper at UNISPACE-82 (Anon 1982c).

\section{Conclusion}

The remote sensing programme is thus taken up in a major way by several countries in the world. USA, USSR, France, ESA, Japan, China, India, Brazil and Pakistan have ongoing or future plans for remote sensing satellites. There are 16 stations all over the world receiving data from LANDSAT satellites and some more are under consideration. A large number of other countries are using or building up facilities for visual or computer-aided interpretation of remote-sensed data. One estimate shows that the annual business volume in remote sensing in the USA is about $\$ 10$ billion and it is likely that the rest of the world would contribute something about the same order. Judging from present trends, this value is likely to go up to $\$ 100$ billion in another ten years.

Tables 1 and 2 give a picture of the history and future of remote sensing satellites, showing their spectral ranges and ground resolution. The data on the USSR Meteor satellites are what is presently available to the authors and may not be complete. Meteorological satellites and the experimental Nimbus satellites have not been covered.

Figure 1 shows the growth of data volume from remote sensing satellites through the years. The rate of data transmission in $\mathrm{Mbps}$ is an indication of the total data available, assuming that a ground station can normally receive about 15 minutes of useful data per day from each satellite. Since it would be too complicated to precisely calculate the total time of operation of the satellites due to operational problems on board, for the purpose of arriving at this figure, a uniform lifetime of 4 years has been assumed for each satellite. Thus this figure would be only indicative of the trend and not the actual values.

A major issue in the international scene is the continuation of the LANDSAT programme, since many countries have invested large amounts of money in building up

Table 1. Remote sensing satellites and sensors

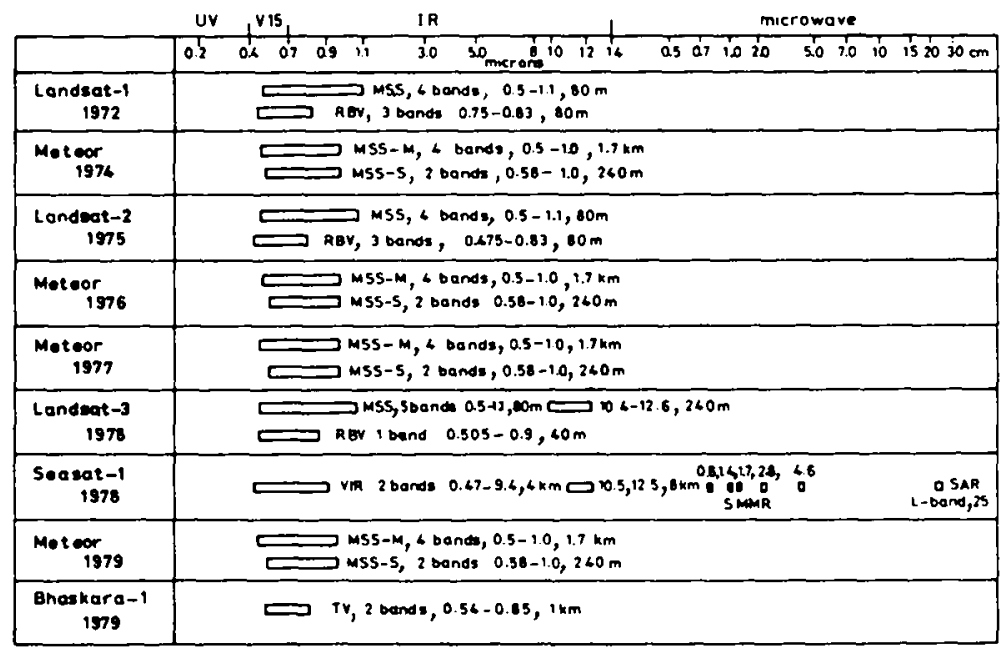


Table 2. Remote sensing satellites and sensors

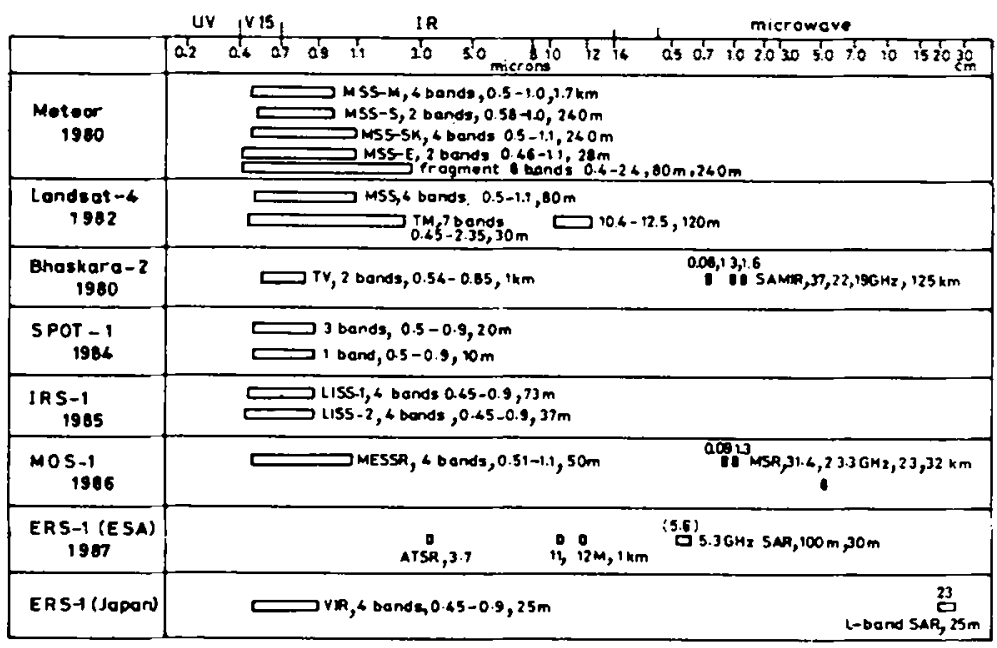

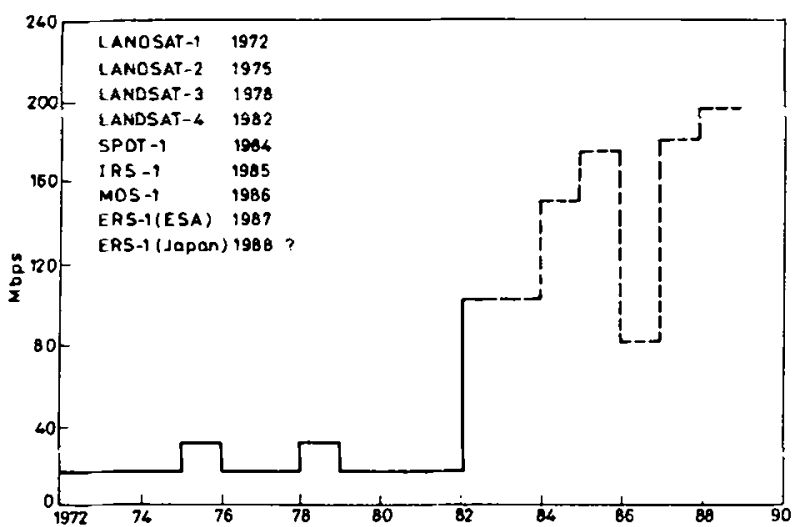

Figure 1. Trend of data volume

ground stations and processing equipment. The move to hand over the operations to a commercial agency makes many to wonder about the availability and the costs of obtaining imagery. The proposal has been discussed at length in Johnson (1980) and the applications in Waldrop (1983). Many of the stations which have been built for receiving the thematic mapper data from LANDSAT -4 can easily be modified to receive SPOT data, though the data are not exactly compatible.

Added to the above is the onset of problems on LANDSAT-4, first curtailing the transmission of thematic mapper data in the X-band and then the Mss data also. The us Government is considering the availability of a replacement satellite and the continuation of the LANDSAT series itself. Though these problems with LANDSAT-4 have come as a major setback in the international scene, the plans for SPOT, IRS, ERS-1 (ESA), MOS-1, ERS-1 (Japan) etc will serve to carry on the flow of data. 
One of the major bottlenecks in future will be the variety of bands, ground resolutions and sensor characteristics offered by the different satellites. This would make data processing varied and to some extent incompatible. Also, the trend towards higher ground resolutions makes some aspects of remote sensing having overtones of surveillance or reconnaissance especially when it involves imaging over foreign territories. This latter aspect is the subject of major debate at the UNO. A paper by Rao \& Chandrasekhar (1983) in this issue addresses some of these aspects. In spite of these problems, the application of remote sensing is likely to take on a greater scope, with greater role of automatic machine processing and interpretation and users spread out in smaller units over wider areas.

\section{References}

Anon 1982a Canada in Space

Anon 1982b Argentina, activity report to COSPAR

Anon 1982c Proceedings of UNISPACE-82

Anon 1982d An introduction to SUPARCO

Anon 1982e Development of satellite remote sensing in Japan, Proc. Satellite Frequency Coordination Group, No. 3, Bangalore, November

Anon 1982f Space research in Sweden, 1981, Report to COSPAR, May

Anon 1982g Remote Sensing Infn Bull. (RAE, Farnborough), Issue No. 7

Anon 1982h Proc. African Remote Sensing Council, Fourth Meeting of the Plenipotentiaries, Kinshasa

Barret E C 1982 The role of EARSeL and EARSeL member laboratories, Proc. EARSeL.ESA symposium (ESA-SP-175) p. 205

Bhavsar P D \& Rajan Y S 1981 Remote sensing in India, ISRO-TR-14-81

Cazenave M 1978 Le Programme SPOT. Proc. Int. Conf. on Earth observations from space and management of planetary resources (ESA SP-134) p. 177 (in French)

Chen, Weijiang 1981 Remote sensing activities in China, Proc. Second Asian Conf. on Remote Sensing, Beijing

Chen, Zong-Zhi, Zhang, Zhi-cheng and Xie, Shou-sheng $1981 \mathrm{X}$-band airborne synthetic aperture radar system and its flight test, Proc. Second Asian Conf. on Remote Sensing, Beijing

Dhawan S. Singh J P \& Kale P P 1979 IEEE Trans. Broadcast. BC-25 121

Johnson D S 1980 Planning for a civil operational land remote sensing satellite system, A discussion of issues and options, US Department of Commerce, NOAA

Keller S W \& Ando K J 1982 Land remote sensing activities in US, Proc. EARSeL-ESA symposium, ESA-SP175 , p. 37

Lennertz D 1982 The European Space Agency's earth observation satellite programmes in the 1980s, Proc. EARSeL-ESA-symposium (ESA-SP-175) p. 21

Lindsay E D (ed.) 1981 Remote sensing of earth resources (London: Dept of Industry)

McCandless S W, Miller B P, Montgomery D R 1981 The SEASAT commercial demonstration programme, Proc. EARSeL-ESA symposium (ESA SP-167) p. 59

Popescu J 1982 J. Br. Interplanet. Soc. 35273

Rajan Y S \& Rao V R 1982 Remote sensing in India, ISRO-TR-24-82

Rao U R \& Chandrasekhar S 1983 Proc. Indian Acad. Sci. (Engg. Sci.) 6373

Sagdeev R Z, Kapitza A P \& Ziman Ya L 1978 Remote sensing in the USSR Academy of Sciences: Studies. experiments, main results, current objectives, Proc. Int. Conf. (ESA SP-134) pp. 203

Sheffield C 1982 Interdiscipl. Sci. Rev. 7112

Sidorenko A V $1982 \mathrm{~J}$. Acad. Sci. USSR (ISRO Translation ISRO-ISAC-TT-01-82)

Tanner 1982 Handbook of sensor technical characteristics NASA RP 1087

Waldrop M M 1983 Science 219752 